\title{
Tráfico mercantil andino, comerciantes indígenas y fiscalización estatal (Tarapacá, norte de Chile 1880-1938) ${ }^{1}$
}

\author{
Por \\ Luis Castro C. \\ Universidad de Valparaíso, Chile/ Universidad de Playa Ancha, Chile
}

En este artículo se aborda el intenso y relevante tráfico mercantil realizado en la entonces provincia de Tarapacá por comerciantes y arrieros indígenas aymaras de ambos lados de la zona fronteriza andina chileno-boliviana durante el ciclo salitrero. Además de poner énfasis en los alcances y características de esta forma de circulación de mercancías y el componente étnico de la misma, se presta atención a la compleja relación con los agentes fiscales chilenos teniendo en cuenta que se estaba en pleno proceso de chilenización.

PALABRAS ClaVE: tráfico mercantil; aymaras; fiscalización estatal; chilenización.

\section{INTRODUCCIÓN}

Entre las décadas de 1880 y 1930 la línea fronteriza que compartió la provincia chilena de Tarapacá con Bolivia fue en su mayor tiempo un espacio abierto y dinámico, no obstante lo anterior, el contexto de guerra ${ }^{2}$, postguerra y reacomodo legal de este territorio anexado ${ }^{3}$. Esta característica, en parte importante causada por la presión que ejerció la minería salitrera a efecto de

${ }^{1}$ Este artículo forma parte del proyecto Fondecyt 1100060. Se agradece al Archivo Histórico de Potosí y a la Biblioteca Municipal de Oruro las facilidades otorgadas en la consulta de sus acervos documentales.

2 Me refiero a la llamada Guerra del Pacífico que enfrentó a Chile con Perú y Bolivia entre 1879 y 1883 .

3 La frontera con Bolivia fue sancionada en el tratado de 1904, siendo ratificado el respectivo Decreto Supremo el año 1907. 
satisfacer sus altos requerimientos de insumos de todo tipo ${ }^{4}$, llevó a que el tráfico mercantil andino -legal como ilegal- entre la pampa tarapaqueña y el suroeste boliviano en vez de decaer como efecto de la conflagración y las tensiones propias de la nueva delimitación fronteriza se incrementara significativamente, una corriente que arrastró a la economía agro-ganadera tanto de los aymaras que quedaron del lado chileno como del boliviano.

Contrario a lo que afirma Juan Van Kessel de que el cambio del eje espacial regional tarapaqueño hacia la pampa salitrera deterioró las posibilidades de los aymaras de «competir en el mercado» ${ }^{5}$, sostengo que fue precisamente esta dinámica lo que permitió asentar en parte importante de esta población indígena ciertas maneras de comercialización que se venían arrastrando desde la constitución de las repúblicas nacionales de Perú y Bolivia a comienzos del siglo XIX, e incluso antes. De este modo, ante las demandas mercantiles salitreras, los aymaras fronterizos fueron capaces de llevar a cabo una inserción bastante exitosa en lo tocante al tráfico mercantil y la producción de insumos agro-ganaderos.

En este contexto, este trabajo busca ahondar en la descripción como en el análisis de una temática que ha sido abordada tangencialmente a propósito del arrieraje boliviano y argentino de matiz estrictamente mercantil-capitalista ocurrido durante el ciclo salitrero ${ }^{6}$. Así, se pone especial atención en las características de este tráfico mercantil andino ocurrido entre las décadas de 1880 y 1930, es decir en pleno proceso de chilenización de la provincia de Tarapacá, la actitud que tomó la administración fiscal respecto a esta actividad ejecutada por campesinos y ganaderos aymaras, y los niveles de interacción como las tensiones emergidas - por los intereses involucrados en este tipo de tráfico- tanto entre los propios indígenas como entre éstos y los agentes de la administración estatal chilena.

\section{LAS CARACTERÍSTICAS DEL TRÁFICO MERCANTIL ANDINO}

Si bien a mediados del año 1880 se prohibió la exportación de salitre a Bolivia $^{7}$, una acción atendible a las circunstancias bélicas del momento, no

4 González, 2002: 21.

5 Van Kessel, 1992: 176.

6 González, 1989: 10-35; 1991: 193-269; 1999: 60-65. Conti, 2002: 119-149; 2003: 21-52; 2006: 93-104. Caro, 1999: 146-149. Michel, Pérez y Savic, 1998: 99-113.

7 Pica, 24/8/1880, Archivo Histórico Nacional (AHN), Intendencia de Tarapacá (IT), Santiago de Chile, vol. 2, sin fol. 
hubo ninguna medida adicional y general por parte de Chile destinada a interrumpir el comercio desde y hacia territorio boliviano. Más aún, esta disposición fue rápidamente revertida tal como lo constata el subdelegado de La Noria, José Silva, al señalar en enero de 1882 que «a pesar del estado de guerra en que nos encontramos con Bolivia no existe interdicción comercial» ${ }^{8}$.

Este hecho -fundado en razones objetivas tales como los requerimientos crecientes de insumos por parte de la industria salitrera y la determinación estratégica de Chile de normalizar y aumentar la producción del nitrato de sodio en el menor tiempo posible a efecto de viabilizar su política rentista9 facilitó la circulación persistente y creciente de mercancías entre Tarapacá y Bolivia potenciando la existencia de una «frontera abierta» ${ }^{10}$ hasta el término del ciclo de expansión del salitre a comienzos de la década de 1930.

En este contexto no fueron pocos los actores locales que tempranamente intentaron, mediante propuestas de construcción de caminos y ferrocarriles bajo una lógica de desarrollo regional, establecer un vínculo económico regular entre Tarapacá y Bolivia, generando una fuerte corriente de opinión pública a favor de facilitar el comercio fronterizo ${ }^{11}$. Precisamente es en estos términos que se debe entender el planteamiento emitido en 1885 por el intendente Gonzalo Bulnes cuando, a raíz de una propuesta del empresario Francisco Bascuñán de hacer un camino carretero hacia la provincia boliviana de Lípez, enfáticamente opinara que crear lazos comerciales permanentes entre Chile y Bolivia era «la primera obra a que debe propender una administración que tenga en vista la grandeza futura del país» ${ }^{12}$; del mismo modo la opinión emitida al año siguiente por quién reemplazara a Bulnes en su cargo, el intendente Anfión Muñoz, respecto a que una vía ferroviaria entre Iquique y Oruro-La Paz impulsaría «numerosas industrias» y aseguraría «permanentemente la vida» del puerto iquiqueño ${ }^{13}$; un planteamiento que reiterará en 1904 el Municipio de Iquique al manifestar que la propuesta del ingeniero Alfredo Castro de construir un ferrocarril entre el pueblo de Pica y la localidad boliviana de Oruro provocaría que la provincia de Tarapacá se «abriría» al co-

8 La Noria, 13/1/1882, AHN, IT, vol. 2, fol.121.

9 En relación a los alcances políticos y económicos de estos dos aspectos y su impacto en el quehacer del aparato fiscal asentado en esta provincia durante las décadas de $1880 \mathrm{y}$ 1930, ver: Castro, 2005.

10 El concepto «frontera abierta» para el caso Tarapacá-Bolivia está tomado de González, 1989: 10-35. Este mismo autor, en un trabajo más reciente (González, 2006a), eleva el concepto de «frontera abierta» a la categoría de «espacio transfronterizo».

11 Castro, 2005.

12 Iquique, marzo 1885, AHN, IT, vol. 79, fols. 85-86.

13 Iquique, 25/4/1886, AHN, IT, vol. 76, sin fol. 
mercio de importación y exportación «con la vecina República» y, en consecuencia, generaría la «necesidad imperiosa de orientar el puerto de Iquique al comercio fronterizo» ${ }^{14}$.

El tráfico mercantil andino entre Tarapacá y Bolivia tuvo dos modalidades: a) el comercio de hormiga o de bajo impacto en cuanto a la cantidad de productos que se internaban o sacaban; b) y la introducción de mercaderías en volúmenes mayores ${ }^{15}$. El primero por lo general operó siempre al margen de la fiscalización tributaria estatal. El segundo, en tanto, fue más controlado, aunque no a plenitud producto de variables tales como la falta de contingente armado para el resguardo de la frontera y las rutas por donde se llevaba a cabo el traslado de las distintas mercancías y ganado, la presión por parte de diferentes agentes fiscales y privados que estaban a favor de incentivar este comercio con la menor cantidad de regulaciones posibles, la disposición de aquellos agentes estatales de rango superior que aceptaban el costo de la baja tributación a cambio de asegurar el abastecimiento a las oficinas salitreras y de este modo incrementar la producción del fertilizante salino a efecto de resguardar la recaudación de la renta ${ }^{16}$, y la acción inescrupulosa de algunos funcionarios chilenos (como policías e inspectores de Distritos) y bolivianos (corregidores e inspectores de Cantón) que buscaron sacar provecho ya sea mediante acuerdos ilegales con algunos comerciantes andinos a objeto de repartirse las utilidades de la ventas soslayando la fiscalización que estaba nada menos que bajo la responsabilidad de cada uno de ellos, o bien mediante el cobro abusivo de derechos a los comerciantes indígenas que operaban tanto legalmente como al filo de lo establecido por las normas aduaneras chilenas.

La intensidad y dinamismo de este tipo de comercio lo constata en 1879 Alejandro Bertrand al comentar, a propósito de lo que ocurría en el pueblo pre-cordillerano de Chusmiza los días de celebración de su santo patrono, que acudía un «gran gentío de Bolivia y de la costa del Perú, casi todos

14 Iquique, 9/1/1904, AHN, Ministerio de Industria y Obras Públicas, vol. 106, sin fol.

15 Entiendo por mercancías y/o mercaderías no tan sólo a los productos elaborados o derivados (harina, alcohol, para chuño, sogas, frazadas, hortalizas, maíz, coca, salitre, etc.), sino también al ganado en pie que se internaba desde Bolivia y el altiplano hacia las oficinas y pueblos salitreros.

16 Es decir, el cobro de un impuesto específico a cada quintal métrico de salitre (y kilo de yodo) que saliera por los puertos nortinos de Antofagasta y Tarapacá con destino a Norteamérica, Europa y Asia. Esta modalidad, la del «rentismo salitrero», fue la principal fuente de ingresos que tuvo el Estado chileno entre las décadas de 1880 y 1920 y fue el mecanismo mediante el cual la oligarquía llevó a cabo su proyecto modernizador y civilizador. Respecto a la renta salitrera y la economía regional tarapaqueña ver: Castro, 2005: 13-36. 
comerciantes que celebran allí una feria» en donde se intercambian «cordeles de lana de llama, zapatos, tejidos y toda clase de mercaderías bolivianas y europeas» ${ }^{17}$.

De los distintos artículos que las autoridades chilenas de la época anotaron en sus informes, llegaban con frecuencia a la pampa salitrera procedentes desde Bolivia hojas de coca, charqui, chicha de maíz, jergas, ponchones o puyes, frazadas, calzados, quinua, papa chuño, tabaco, cecinas, correas, riendas y sogas de lana ${ }^{18}$. A su vez desde la zona interior adyacente (oasis, valles y altiplano) predominaba el comercio de verduras, frutas, quesos, huevos, gallinas, maíz, alfalfa y quinua ${ }^{19}$. Una dinámica propia tuvo el tráfico mercantil de ganado, el que abastecía al espacio salitrero principalmente de corderos, ovejas, cabras y llamas, y en menor medida de bueyes, caballos y burros $^{20}$. En contrapartida, hacia Bolivia se internaba salitre (casi siempre de modo ilegal), alcohol (aguardiente y vino que se elaboraba en el oasis de Pica y licores de ultramar), harina de trigo, conservas (que se obtenían de los almacenes o pulperías ubicadas tanto en los pueblos como en las oficinas salitreras) ${ }^{21}$, calaminas (planchas de zinc que servían para cubrir las murallas o techumbres de las casas), planchas de fierro y jabón ${ }^{22}$. Según Gilberto Pauwels, hacia comienzos del siglo XX el alcohol representaba un $44 \%$ de lo que se ingresaba a Bolivia y la harina de trigo un $23 \%{ }^{23}$.

Las rutas por el sector chileno más frecuentemente utilizadas para llevar a cabo este tráfico mercantil hacia Bolivia eran las que pasaban por las localidades de Chusmiza, Cultane, Sibaya, Sotoca, Parca, Pachica y Mamiña; en tanto del lado boliviano las más importantes eran las que partían desde los pueblos de Llica y Salinas hacia la pampa salitrera y algunos puntos intermedios $^{24}$. Zenón Bacarreza, en su informe publicado en La Paz en 1912, iden-

17 Bertrand, 1879: 22.

18 Iquique, 24/5/1880, AHN, IT, vol. 13, fol. 10; Iquique, 29/4/1883, AHN, IT, vol. 7, sin fol.; Tarapacá, 1/2/1885, AHN, IT, vol. 7, sin fol. González, 2006b: 41.

19 Iquique, 1/3/1928, Archivo Regional de Iquique (ARI), Intendencia de Tarapacá (IT), Iquique, Solicitudes 1927, vol. 25, sin fol.

20 Iquique, 29/4/1883, AHN, IT, vol. 7, sin fol.; Iquique, 1/3/1928, ARI, ITI, Solicitudes 1927, vol. 25 , sin fol.

21 Tarapacá, 6/4/1911, ARI, IT, Subdelegaciones 1911, vol. 47, sin fol.; Pica 11/3/1917, ARI, IT, Intendencia de Tarapacá, 1917, vol. 17, sin fol.; Pica 5/3/1917, ARI, IT, 1917, vol. 17, sin fol.; Iquique, 12/3/1917, ARI, IT, 1917, vol. 17, sin fol.

22 González, 2006b: 41. Cottyn, 2011: 34.

23 Pauwels, 2006: 341.

24 Pozo Almonte, 1/3/1895, AHN, IT, vol. 191, sin fol.; Tarapacá, 6/4/1911, ARI, IT, Subdelegaciones 1911, vol. 47, sin fol.; Iquique, 11/7/1928, ARI, IT, Solicitudes, 1927, vol. 25 , sin fol. 
tifica a los pueblos pre-cordilleranos de Camiña, Tarapacá y Chiapa como los puntos de conexión entre la provincia de Carangas y la provincia de Tarapacá $^{25}$. De los caminos tarapaqueños empleados para entrar o salir hacia y desde Bolivia con mercancías de todo tipo probablemente el más recurrido (al menos durante todo el siglo XIX y la primera mitad del XX) fue el que cruzaba por Chusmiza, siguiéndoles los de Sibaya y Pachica. Precisamente esto constatará a comienzos del año 1871 -es decir, durante la administración y soberanía peruana de este territorio- el funcionario José María Toro al reportarle al subprefecto de Tarapacá el éxito de sus diligencias para controlar y aprehender un grupo de individuos, denunciados por el agente municipal de Chusmiza, que internaban desde hacía mucho tiempo regularmente coca y otros artículos tanto por el pueblo de Chusmiza como por Pachica sin pagar los derechos respectivos ${ }^{26}$; del mismo modo -ya bajo tutela chilena entre las décadas de 1870 y 1890 - ratificarán esta situación de la relevancia de los pasos fronterizos de Chusmiza, Pachica y Sibaya tanto Alejandro Betrand en su estudio sobre la geografía física y económica del Departamento de Tarapacá como Enrique Espinoza en su trabajo sobre la geografía descriptiva de Chile 27.

En el caso específico de la internación de ganado, uno de los circuitos más usado fue el que por el sector chileno comenzaba en la Laguna del Huasco, donde pastaban los animales, bajando enseguida por la Quebrada Seca hacia una aguada y alfalfares de propiedad de Domingo Palacios, para -desde este último lugar- repartir el ganado por diversas vías a los distintos pueblos y oficinas salitreras. Además de esta ruta, se usaban con frecuencia para la internación de ganado las de Chacarilla y Quebrada de Cahuiza ${ }^{28}$. También fue importante la ruta que pasaba por la localidad de La Calera que, de acuerdo al subdelegado Ambrosio Valdés Carrera, a pesar de ser un caserío de apenas 12 habitantes su «importancia [era] bastante grande, en atención a que por ahí bajaban los arreos de animales traídos de Bolivia». Este trayecto, que unía el pueblo pampino de Pozo Almonte y el límite fronterizo con Bolivia, era un muy «buen camino» ya que tenía apenas una extensión de 30 leguas «con agua i pasto a cortas jornadas ${ }^{29}$. Esta recorrido, en el sector de Yabricoya, se unía al trayecto Pica-Bolivia, un camino que conectaba al oasis piqueño

25 Bacarreza, [1912] 2006: 385.

26 Iquique, 23/1/1871, AHN, Prefectura de Tarapacá, vol. 47, sin fol. Esta información también está referenciada en: Gajardo y Díaz, 2008: 25.

27 Bertrand, 1879: 23. Espinoza, 1897: 69.

28 Iquique, 8/6/1918, ARI, IT, Arriendo de Tierras Fiscales, 1918, vol. 3, sin fol.

29 Pica, 6/7/1883, AHN, IT, vol. 43, fol. 19. 
con Cumiñalla, Chacarilla, el rio Salado y terminaba en la altiplanicie en un refugio denominado Calla, lugar fronterizo deshabitado que servía de alojamiento (o pascana) al tener agua y pasto y donde la caza de vicuñas, viscachas y patos proporcionaba «un alimento abundante a los viajeros» ${ }^{30}$.

El volumen de este tráfico comercial es muy difícil de cuantificar o seriar con precisión, especialmente por lo que representó el contrabando, no obstante algunos datos fragmentados nos permiten inferir la dimensión que llegó a tener. Por ejemplo, respecto a la comercialización de la hoja de coca, resulta ilustrativo el informe del subdelegado de La Noria, José Silva, al jefe político de Tarapacá emitido a comienzos de 1882. En este documento se señalaba que la presencia de este producto que se internaba por Bolivia «no [dejaba] de ser considerable, teniendo en cuenta que existen en las oficinas salitreras dos o tres mil bolivianos para quienes este artículo es de primera necesida$\mathrm{d} »^{31}$. El dato entregado a fines de 1930 por la Oficina Sanitaria Provincial es bastante útil respecto a cuantificar lo que Silva calificaba como «considerable». De acuerdo a un control realizado al expendio de este producto en las oficinas y pueblos salitreros, esta repartición informaba que había constatado que entre los meses de enero y junio de 1930 la internación de este producto alcanzaba a los 11.717 kilos $^{32}$, de los cuales 8.744 ya se habían vendido y 2.973 quedaban disponibles en bodegas. Es decir, si hacia fines del ciclo salitrero el volumen de internación de la hoja de coca había llegado a ser considerable, la presencia de este producto debió ser aún mayor en los períodos más activos de estas faenas mineras (entre las décadas de 1890 y 1910) tomando en cuenta una presencia más nutrida de trabajadores bolivianos que alcanzó - de acuerdo a los censos de 1902 y 1907 - a 3.352 y 15.652 individuos respectivamente ${ }^{33}$.

$\mathrm{Al}$ igual que la hoja de coca, la venta de ganado introducido desde Bolivia y el altiplano del lado chileno tuvo un volumen de enorme consideración entre las décadas de 1880 y 1930 , especialmente al tener un mercado cautivo ascendente en la numerosa población que residía en los pueblos y oficinas salitreras $^{34}$. En este sentido, los registros son muy esclarecedores. El 30 de abril de 1883 el subdelegado de La Noria informa el cobro de derechos en el Distrito de Canchones por un valor de $\$ 30$ a un comerciante que habían in-

\footnotetext{
30 Bertrand, 1879: 18.

31 La Noria, 19/1/1882, AHN, IT, vol. 2, fol. 121.

32 Iquique ,19/2/1931, ARI, IT, Memorias, 1931, vol. 8, sin fol.

33 González, 2009: 76.

34 Demás está decir que esta proyección cuantitativa se incrementa exponencialmente al considerar el tráfico ganadero que venía desde el noroeste de la Argentina.
} 
ternado desde territorio boliviano una partida de 150 cabezas de ganado entre corderos y cabras ${ }^{35}$. En tanto, en el mes de agosto de este mismo año, el subdelegado de Pica, Valdés Carrera, oficia al jefe político que un tal Manuel Pérez, residente temporal del pueblo de La Tirana, había ingresado desde Bolivia 500 corderos sin pagar derechos ${ }^{36}$. A inicios del 1900, confirmando la tendencia, tenemos el oficio del primer alcalde municipal de Pica, José Carvajal, donde le detalla al intendente que en su comuna en el año 1899 se habían consumido 6.487 cabezas de ganado que se distribuían en 2.526 vacunos, 1.731 ovejas, 1.764 llamas, 160 vicuñas y 306 porcinos $^{37}$. En 1906, por su parte, la policía informa a la máxima autoridad de la provincia que en la localidad de Chusmiza mantenía retenida una «gran cantidad» de ganado ovejuno perteneciente a Francisco Argote por considerar esta partida como contrabando al no poder mostrar el imputado las boletas de pago de los derechos aduaneros ${ }^{38}$. Por si fuera poco, en 1907 el oficial del Registro Civil de Pisagua llama la atención sobre la existencia de 7.000 corderos en la misma localidad introducidos ilegalmente desde Bolivia por la quebrada de Tarapacá $^{39}$. En junio de 1917 el subdelegado de Pozo Almonte da aviso a sus superiores que un arriero llamado José Barrera había introducido clandestinamente desde Bolivia, pasando por las localidades de Pica y La Tirana, 1.000 ovejas para llevarlas a las oficinas salitreras ${ }^{40}$. Este mismo año el subdelegado de Huara, en base a la notificación remitida por una comisión fiscalizadora de policías por él mandatada a raíz de algunos antecedentes que disponía, da cuenta al intendente que en los pueblos de Chusmiza y Sitane se habían reunido más 200 ovejas traídas desde Bolivia con el propósito de internarlas en la pampa salitrera sin pagar derechos aduaneros ${ }^{41}$. En la década siguiente, en abril de 1928, el encargado de la Aduana de Iquique advertía a la Intendencia de Tarapacá de la ocurrente internación clandestina por parte de indios bolivianos de «grandes partidas de llamas y ganado» por el distrito de la Guaica $^{42}$. Por último, a inicios del año 1931, Noel Arroyo comunica al intendente, a efecto de denunciar el robo de 116 animales de su propiedad por parte de un boliviano de apellido Ticona, que en agosto de 1930 le había

\footnotetext{
35 La Tirana, 30/4/1883, AHN, IT, vol. 7, sin fol.

36 Pica, agosto 1883, AHN, IT, vol. 43, fol. 36.

37 Pica, 6/3/1900, AHN, IT, vol. 330, sin fol.

38 Iquique, 1906, ARI, IT, Policía de Seguridad, 1906, vol. 14, sin fol.

39 Iquique, 13/9/1907, ARI, IT, Ministerio de Hacienda ,1907, vol. 21, sin fol.

40 Iquique, 5/6/1917, ARI, IT, Censo, 1920, vol. 19, sin fol.

41 Idem.

42 Iquique, 18/4/1928, ARI, IT, Tesorería Provincial, Aduana, Carabineros de Aduana, 1928, vol. 26, sin fol.
} 
comprado al arriero boliviano Valentín Hualta 61 crías de llamas en \$2.856, además de 55 llamas adultas que el susodicho le había entregado en calidad de compromiso de venta ${ }^{43}$.

Este negocio no solo se reducía a la carne, sino también comprendía la compraventa de lana. De acuerdo a antecedentes bolivianos, entre fines del siglo XIX y comienzos del XX un $47 \%$ de sus exportaciones a los países vecinos correspondía a la lana de alpaca, un porcentaje que solo consideraba la comercialización legal y dejaba fuera las transacciones «clandestinas» que se estimaban igual o superior a lo que era registrado por las reparticiones aduaneras de Lípez y Carangas ${ }^{44}$.

Respecto a los otros productos que se comercializaban desde, y hacia, territorio boliviano, tenemos el dato emitido a mediados de 1883 por el ya mencionado subdelegado de Pica, Valdés Carrera, de que «un tal Cabrera de Bolivia» traficaba hacia ese país desde las localidades de La Tirana y Pica un total de 10 cargas de mercaderías que se componían de harina, conservas y alcohol, es decir los productos típicos -además del salitre- que se traficaban en esa dirección casi siempre de modo ilegal toda vez que evitaban pagar impuestos $^{45}$. Dos años antes, en agosto de 1881, el subprefecto de Nor Lípez notifica que a principios de noviembre de 1880 se había pesquisado en el punto del Huasco el paso de 58 cajones de cerveza que provenían de la provincia chilena de Tarapacá realizado por los arrieros bolivianos Bonifacio Barroso y Felipe Huaca ${ }^{46}$. En 1910, a propósito de una demanda por devolución de especies que el comerciante boliviano Hipólito Saunero había entregado a Amadora Avello para la venta en los pueblos y oficinas salitreras, se detallan las siguientes especies como productos internados desde Bolivia: un poncho de vicuña a $\$ 135$, una chalina a $\$ 134$, tres sombreros de pita a $\$ 22$ cada uno, un poncho de lana color listado a $\$ 35$, una frazadilla de castilla a $\$ 26$ y una docena de medias de lana a \$20, lo que hacía un valor total de $\$ 417^{47}$. Al año siguiente, en un periódico orureño, se da cuenta que cuatros comerciantes indígenas que se dirigían a Chile con 40 llamas cargadas habían sido violentamente asaltados ${ }^{48}$. También la observación emitida a mediados del año 1928 por el encargado de la Aduana de Iquique, Ernesto Gómez Del-

\footnotetext{
43 Pica, 14/1/1931, ARI, IT, Solicitudes, 1930, vol. 16, sin fol.

44 Pauwels, 2006: 341.

45 Pica, agosto 1883, AHN, IT, vol. 43, fol. 36.

46 San Cristóbal, 30/8/1881, Archivo Histórico de Potosí (AHP), Fondo Prefectura del Departamento (FPD), Subprefectura Nor Lípez, Potosí, n 1819, sin fol.

47 Iquique, 1910, AHN, Judiciales de Iquique, legajo 2835, pieza 5, fj.1r.

48 La Prensa (Oruro, 10 de enero de 1911): 2.
} 
gadillo, de que en el retorno hacia Bolivia los comerciantes indígenas «llenan en más de diez veces lo que traen ${ }^{49}$. Finalmente, los antecedentes remitidos a fines de 1930 por la jefatura de carabineros de Pica a efecto de poner al tanto de que en un control fronterizo practicado por una patrulla de su dependencia se había descubierto a un grupo de comerciantes bolivianos, liderados por Manuel Aguirre, que traían consigo 49 llamas con carga de chuño, quinua, papas y otras mercancías destinadas a los pueblos y oficinas salitreras ${ }^{50}$.

En cuanto al tráfico de salitre los antecedentes disponibles son numerosos, remarcando con ello que este producto -a pesar de ser comerciado en gran parte de manera ilegal por estar prohibida su venta a los países vecinos hasta comienzos de la década de 1900- tenía en Bolivia un mercado cautivo a efecto de fertilizar tanto las tierras agrícolas adyacentes a la línea fronteriza como aquellas más alejadas situadas, por ejemplo, en los valles cochabambinos. Por lo general, el tráfico de salitre se llevaba a cabo por las localidades de Mamiña y Camiña, cuyas áreas aledañas se utilizaban como centros de acopio para, con posterioridad, llevar este fertilizante salino en pequeñas partidas hacia los pasos fronterizos. Será precisamente en la localidad de Mamiña que en 1895 el inspector de Distrito encontró una «gran existencia» de salitre que esperaba ser contrabandeada, y si bien este funcionario no especificó el volumen, si remarcaba su impresión por la numerosa cantidad de quintales métricos que representaba este hallazgo ${ }^{51}$. De acuerdo al subdelegado de Pozo Almonte, este comercio ilegal a través de Mamiña lo realizaban distintos arrieros «aprovechando las altas horas de la noche» para cargar sus tropas y dirigirlas a Bolivia ${ }^{52}$. Una denuncia, cursada en 1911 por el jefe del Escuadrón de Carabineros con asiento en el pueblo de Huara, nos posibilita conocer la cantidad promedio de estas partidas de salitre. De acuerdo al parte emitido por este funcionario, en marzo de ese año se había mandado a notificar a un tal Mariano Callpa como responsable de la existencia de 8 quintales de salitre escondidos en un punto llamado «Quebrada Honda», lugar ubicado a 2.5 kilómetros del pueblo de Camiña, y que estaban destinados a internarse clandestinamente hacia Bolivia ${ }^{53}$. Antecedentes aportados en 1913 por el inspector del Distrito de Camiña, Ramón Fuentes, corroboran lo anterior. Según este funcionario, como resultado de su ejercicio fiscalizador, entre los meses de agosto y septiembre de ese año logró pesquisar dos cargas de

\footnotetext{
49 Iquique, 11/7/1928, ARI, IT, Solicitudes, 1927, vol. 25, sin fol.

50 Pica, 1/12/1930, ARI, IT, Solicitudes, 1930, vol. 16, sin fol.

51 Mamiña, 7/5/1895, AHN, IT, vol. 295, sin fol.

52 Pozo Almonte, 1/3/1895, AHN, IT, vol. 191, sin fol.

53 Iquique, 24/3/1911, ARI, IT, Ejército, Armada y Carabineros, 1911, vol. 43, sin fol.
} 
salitre escondidas con el fin de contrabandearlas hacia Bolivia desde Camiña. La primera, ubicada en la casa de Manuela Choque viuda de Platero, consistía en 24 medios sacos de este fertilizante salino listos para ser transportados por dos arrieros llamados Cecilio Platero y Miguel Vilca, este último además propietario de la carga. La segunda, en tanto, se componía de 16 quintales debidamente ensacados y destinados al mismo destino ${ }^{54}$.

\section{EL TRÁFICO MERCANTIL ANDINO Y LA PRECARIA FISCALIZACIÓN ESTATAL}

Apenas se instaló la administración chilena en territorio tarapaqueño se hizo evidente la intensidad y regularidad del tráfico mercantil andino, actividad comercial que ni siquiera el escenario de guerra había paralizado y que en gran parte se llevaba a cabo fuera de las obligaciones de tributación. Precisamente esto es lo que constata en mayo de 1880 David Mac Iver -entonces encargado de la Aduana y Tesorería de Iquique- al informarle al jefe político de Tarapacá -Patricio Lynch- que, de acuerdo a datos aportados por Belisario Jara, el comandante militar de Pica, desde Bolivia se introducía ilegalmente hacia las oficinas salitreras una nada de despreciable cantidad de tabaco, coca y otros artículos. A su entender el volumen de esta práctica comercial hacía conveniente que a los comandantes militares de Pozo Almonte, La Noria y Pica se les otorgaran facultades explícitas para cobrar los respectivos derechos de aduana ${ }^{55}$. Seis meses más tarde, el 3 de noviembre de 1880, el comandante militar de La Noria, Lorenzo Hurrel, ratificando las observaciones de Mac Iver, reporta al jefe político de Tarapacá que le había recomendado al recién llegado subdelegado de La Tirana, Gumercindo San Martín, que efectuara una especial vigilancia a efecto de impedir los contrabandos de coca y tabaco que se internaban desde Bolivia. Desde su perspectiva, esta situación revestía particular importancia porque:

Ningún comerciante de coca hasta hoi día sé que haya pagado los derechos correspondientes porque la venden directa i furtivamente en las oficinas. El subdelegado de La Tirana puede mui bien vigilar esta importante entrada del erario nacional, pues, es por ese lugar que se hacen todas las internaciones para las oficinas de este cantón ${ }^{56}$.

\footnotetext{
54 Camiña, 6/9/1913, ARI, IT, Censo, 1920, vol. 19, sin fol.

55 Iquique, 24/5/1880, AHN, IT, vol. 13, fol. 10.

${ }^{56}$ La Noria, 3/11/1880, AHN, IT, vol. 2, fol. 26.
} 
No obstante los planteamientos de Mac Iver ${ }^{57}$ y Hurrel, el flujo del tráfico (tanto legal como ilegal) desde Bolivia siguió practicándose con intensidad, denotando de paso la poca capacidad e interés del aparato fiscal chileno asentado en la recientemente anexada provincia de Tarapacá de ponerle un coto definitivo, un escenario que será ratificado con regularidad por los funcionarios más próximos al quehacer administrativo en terreno, es decir los subdelegados, como por parte del propio Patricio Lynch en su calidad del más importante encargado político de la provincia durante los primeros años de administración chilena. Este último personero, por ejemplo, respondiendo al requerimiento ya mencionado de David Mac Iver de mayo de 1880, apenas promoverá regular el tráfico mercantil que provenía de Bolivia cuando llegara a la pampa salitrera, a su entender la única acción posible que era capaz de llevar a cabo el aparato fiscal que tenía a su cargo ${ }^{58}$. Conceptos equivalentes serán los emitidos el 19 enero de 1882 por el subdelegado de La Noria, José Silva, al manifestarle al jefe político con suma preocupación que el contrabando fronterizo, principalmente de coca, ocurría porque «aquí no existe quien vigile su importación, i quién perciba por consiguiente los derechos respectivos» ${ }^{59}$ y el reporte del subdelegado de Pozo Almonte, Luis Cevallos, dirigidas el 6 de diciembre de 1882 a la máxima autoridad de la provincia en cuanto a que el inspector de la localidad de La Tirana le había hecho saber que por su jurisdicción se internaban comerciantes desde el altiplano y desde Bolivia trayendo distintos productos, especialmente charqui y coca, para distribuirlos en los pueblos y oficinas salitreras, y que por lo mismo le era de suma importancia el saber si debía cobrar los derechos aduaneros de tres pesos por quintal o bien liberar a los comerciantes de este importe ${ }^{60}$. Respecto a esta última información, igual desconcierto se constata en Bolivia cuando el corregidor del Cantón Colcha le consulta, en octubre de 1885, al subprefecto de la Provincia de Nor Lípez si la internación de alcoholes de Tarapacá era o no una actividad lícita ${ }^{61}$.

Se hace evidente, a la luz de la información referida a los dos primeros años de la presencia de la administración chilena en territorio tarapaqueño, que la capacidad de fiscalización del tráfico mercantil andino fue prácticamen-

57 David MacIver no sólo fue el encargado de la Aduana y la Tesorería en Iquique, sino además se hizo cargo de la Jefatura Política de Tarapacá de manera interina a fines de 1881 . Alfaro, 1936: 151.

58 Iquique, 24/5/1880, AHN, IT, vol. 13, fol. 10.

59 La Noria, 19/1/1882, AHN, IT, vol. 2, fol. 121.

60 Pozo Almonte, 6/12/1882, AHN, IT, vol. 2, sin fol.

61 San Cristóbal, 13/10/1885, AHP, FPD, Subprefectura Nor Lípez, nº 2024, fol. 38. 
te nula. Esta actividad, ya de larga data hacia fines del siglo XIX, tenía una dinámica que superaba con creces el cambio de escenario que implicaba la presencia de Chile. Precisamente esto es lo que refleja la notificación remitida el 30 de abril de 1883 por el ya mencionado subdelegado de La Noria, José Silva, de que un antiguo empleado fiscal peruano de Pica estaba cobrando indebidamente (por ser un «conocedor de este negocio» y tener intereses pecuniarios personales) tributo a comerciantes bolivianos que pasaban por el oasis piqueño hacia la pampa salitrera "por no haber allí ninguna otra autoridad» ${ }^{62}$. Esta falta endémica de fiscalización la ratifica en agosto de 1883 el subdelegado de Pica, Ismael Valdés Carrera, al remitirle al intendente un oficio en donde, al enumerar las dificultades más relevantes de su gestión, resaltaba la imposibilidad que tenía de controlar el contrabando desde y hacia Bolivia que practicaban principalmente dos arrieros, Manuel Pérez residente en el pueblo de La Tirana y un boliviano de apellido Cabrera, a través de la localidad de la Calera por carecer de un piquete de cazadores, falencia en su opinión que no tenía excusa alguna dado que «no causaría mayor desembolso al gobierno desde que las entradas de esta Subdelegación dan para atender al mayor gasto que puedan ocasionar» ${ }^{63}$.

La precariedad del control estatal al comercio andino, presente con intensidad en los primeros dos a tres años de la anexión de Tarapacá a Chile, no variará con el tiempo. Consecuentemente el tema no se resolvió, como era de esperar, por un asentamiento más sólido de la agencia estatal chilena producto del transcurrir del tiempo. De esta manera, la falta de fiscalización rápidamente se mostró como resultado de un aparato estatal más preocupado de la renta salitrera que de las dinámicas andinas e indígenas, más aún si estas actividades eran funcionales a los intereses estratégicos chilenos. No es de otro modo que se pueda entender que, con fecha 1 de febrero de 1885 , el subdelegado de Tarapacá, Ismael Aguilar, se dirigiera al intendente a efecto de requerirle instrucciones precisas de si le correspondía o no cobrar tributos a las mercaderías y animales que transitaban entre Tarapacá y Bolivia por su jurisdicción ${ }^{64}$, es decir, la misma preocupación y falta de información en lo tocante a las materias del tráfico mercantil andino explicitadas -con diferente intensidad y en otras circunstancias- por funcionarios del mismo rango que Aguilar en los años anteriores.

En las décadas siguientes este escenario de una actividad mercantil transfronteriza practicada por comerciantes principalmente indígenas que superaba

\footnotetext{
62 La Tirana, 30/4/1883, AHN, IT, vol. 7, sin fol.

63 Pica, agosto 1883, AHN, IT, vol. 43, fol. 36.

64 Tarapacá, 1/2/1885, AHN, IT, vol. 7, sin fol.
} 
las posibilidades de la administración chilena (y también boliviana) de someterla al ordenamiento aduanero vigente no evolucionó demasiado. La fiscalización de las dinámicas de intercambio se ciñó, por la parte chilena, a una intervención que fue, por lo general, concordante con la política de apoyar los requerimientos que provenían de la minería del salitre, permitiéndose de este modo un comercio sin mayores restricciones; en tanto por el lado boliviano se asumía que el cobro de impuestos a las mercancías que se internaban hacia Chile (sobre todo la lana de alpaca, oveja y llama) era imposible de «regularizar por el contrabando que se practica a gran escala en la extensa frontera de la provincia de Carangas» ${ }^{65}$.

Un buen ejemplo de la funcional y escasa preocupación chilena por controlar aduaneramente el tráfico mercantil andino es la declaración del prefecto de la policía provincial, emitida en 1907, que del total de caballos y mulas que disponía para efectuar patrullajes en toda la provincia, apenas un 5,8\% de ellos estaban destinados a la zona rural andina ${ }^{66}$, es decir 9 mulas que, por si fuera poco, se ocupaban casi exclusivamente en los requerimientos del mineral cuprífero de Collahuasi que para ese año estaba en su máxima actividad extractiva al punto de tener una población superior a las 3.000 personas ${ }^{67}$. Al amparo de esta realidad era imposible que hubiese fiscalización alguna al contrabando y comercio transfronterizo. Por lo mismo este dato no es menor, ya que denota por parte de la autoridad política chilena asentada en Tarapacá escaso interés por tener bajo control ninguna otra actividad económica y productiva que no estuviera ligada a la minería (especialmente la salitrera), un aspecto que queda en evidencia por el reclamo del subdelegado de Tarapacá, Mauricio Reynaud, al intendente con fecha 6 de abril de 1911 en el sentido que un oficio suyo dirigido dos años antes pidiendo la destinación de carabineros para controlar el contrabando mercantil de coca, lana, ganado y salitre que ocurría por su jurisdicción había quedado simplemente sin contestación ${ }^{68}$.

Esta falta de preocupación de la administración estatal llevó a que muy tardíamente, en el año 1910, se creara en esta provincia un Resguardo de Frontera, repartición que sin embargo tuvo una corta existencia al ser suprimida en 1912 por el Ministerio de Hacienda ${ }^{69}$. La cesación del mencionado Resguardo hizo que a mediados del año 1913 el subdelegado subrogante de

\footnotetext{
65 Morales, 1913: 12-13.

66 Iquique 25/6/1907, ARI, IT, Libro de la Policía, 1907, vol. 8, fol. 52.

67 Castro, 2002: 353-368; 2010: 129-145.

68 Tarapacá, 6/4/1911, ARI, IT, Subdelegaciones, 1911, vol. 47, sin fol.

69 Iquique 31/3/1914, ARI, IT, Copiador de Oficios a los Ministerios, 1914, vol. 14, fol. 162.
} 
Tarapacá, Pablo Atrimpel, reconociera con franqueza un incremento exponencial del contrabando de una gran variedad de mercaderías desde la frontera boliviana hacia las oficinas y pueblos de la pampa salitrera ${ }^{70}$; un hecho que reiterará en 1914 el subdelegado de Camiña, de apellido Prieto, al comentar que tenía «conocimiento, que con mucha frecuencia se internaba ganado lanar de Bolivia, sin pagar los derechos correspondientes, por no existir policía de frontera $\rangle^{71}$ y ratificado tanto en 1915 por el subdelegado de Pica, Raúl Moya ${ }^{72}$, al solicitar instrucciones respecto a si debía o no cobrar impuestos a los comerciantes habiéndose cumplido el plazo que autorizaba la libre internación de ganado y otros artículos desde Bolivia ${ }^{73}$, como en 1916 cuando el subdelegado de Challacollo, M. Arias, en un tono muy sentido y a su vez revelador le informa al intendente:

No acostumbrados los Srs. comerciantes a ser molestados por sus arbitrariedades o abusos por ninguna autoridad local, hoy conmigo, que procediendo independientemente $\mathrm{i}$ en cumplimiento a las instrucciones de V.S. se encuentran muy descontentos porque no pueden acomodarse como tienen costumbre.

Ha llegado a mi conocimiento que el ex-juez Dn. José M. Hoyos y Federico Varas que fue subdelegado en periodos anteriores en esta misma Subdelegación, se han presentado al Gerente de la Mina Poderosa; como así mismo los Srs. Guirado, Mamani, Vilca, nombrados por V.S. en telegrama fecha 9 del presente, y han aconsejado a los arrieros notificados a presentarse a dicho Sr. reclamándole que si yo les cobrara 2 o más pesos por cabeza de ganado no podrían entregar yareta y sería un perjuicio como ellos lo consideran; pretexto para encabezar reclamo a esa Intendencia y continuar explotando al Fisco ${ }^{74}$.

70 Tarapacá, 5/6/1913, ARI, IT, Subdelegaciones, 1913, vol. 9, sin fol.

71 Pisagua, 10/2/1914, ARI, IT, Varios Oficios, 1914, vol. 31, sin fol.

72 Este funcionario en más de una ocasión fue acusado de ser uno de los principales comerciantes de ganado boliviano que, abusando de su cargo, internaba por el oasis de Pica a la pampa salitrera sin pagar la totalidad de los derechos aduaneros.

73 Pica, 1/7/1915, ARI, IT, Funcionarios Judiciales, 1915, vol. 4, sin fol.

La disposición administrativa de suprimir temporalmente el cobro de derechos a las mercancías internadas desde Bolivia, al parecer fue accedida por la Intendencia ante una solicitud de numerosos vecinos de las localidades de Pica, Matilla y Quisma que, veían en esta medida, una solución a la carestía de víveres que estaban enfrentando producto de la crisis económica que vivía la provincia por el cierre de numerosas oficinas salitreras (Pica, noviembre 1915, ARI, IT, Solicitudes 1915, vol. 42, sin fol.). Entre 1916 y 1917 esta medida temporal tomó cuerpo en un proyecto de ley, presentado al Congreso, que buscaba liberar del pago de derechos a todo el ganado que se internara a las provincias del norte, iniciativa que entusiasmó a muchos, entre ellos al ganadero aymara Leonidas Cholele, para solicitar permiso para ingresar ganado desde Bolivia aduciendo la carestía de este producto (Huara, agosto 1917, ARI, IT, Solicitudes 1917, vol. 34, sin fol.).

74 Collahuasi, 6/10/1916, ARI, IT, Juzgado Subdelegaciones, 1916, vol. 28, sin fol. 
La persistencia de esta situación quedará al descubierto cuando, en junio de 1918, el comisario de investigaciones de Iquique le comunica al intendente que, en lo tocante al tráfico ganadero que ingresaba desde Bolivia, se:

sabe que no existe en ninguno de los pueblos arriba indicados, vigilancia o fiscalización alguna o personal autorizado para salvaguardar los intereses fiscales, quedando a voluntad de los introductores el tramitar o no las pólizas correspondientes, siendo el caso corriente que con una póliza por una pequeña cantidad de animales se introduzcan diferentes partidas mucho mayores ${ }^{75}$.

Por si fuera poco bastante tiempo después, en 1938, el subdelegado de Huara, en ese entonces la máxima autoridad de la repartición administrativa a cargo de los distritos asentados en la quebrada de Tarapacá, no tiene reparos en decirle al intendente que debido a la carencia «absoluta de autoridades competentes que velen por la tranquilidad pública», en esos apartados lugares no es posible evitar el «comercio clandestino de animales y artículos bolivianos, que [se] internan en territorio nacional, burlándose del pago de los derechos arancelarios que corresponde» ${ }^{76}$.

Desde el sector fronterizo boliviano por la misma época el escenario tampoco era muy distinto. En 1905 el subprefecto de Nor Lípez, Isaac Calderón, pone en conocimiento a su superior que la policía estaba «muy mal organizada» y que los vigilantes eran «insuficientes» para llenar las necesidades que requería una "provincia limítrofe» como la que tenía a cargo ${ }^{77}$; al año siguiente, en un diario de Oruro, se denunciaba que en la provincia de Carangas, también limítrofe con Chile, era «muy reducida la fuerza de policía» que estaba a cargo del Subprefecto ${ }^{78}$; del mismo modo Zenón Bacarreza, en su ya comentado informe, resaltaba que hacia 1910 en Carangas «no existen aduanas o resguardos en la extensa frontera» provocando que «el tráfico comercial de esta provincia es completamente libre por los caminos que se comunican con las distintas plazas comerciales del territorio chileno» ${ }^{79}$; una deficiencia que será ratificada por el subprefecto de la provincia de Nor Lípez en 1911 al informar que en su jurisdicción los resguardos aduaneros «no existen» haciéndose, por lo mismo, «incalificable la internación de contraban-

75 Iquique, 8/6/1918, ARI, IT, Arriendo Terrenos Fiscales, 1918, vol. 3, sin fol.

76 Huara, 23/11/1938, ARI, IT, Rica Aventura, Pozo Almonte, Arica y Pisagua, 1938, vol. 12 , sin fol.

77 San Cristóbal 8/2/1905, AHP, FPD, Subprefectura Nor Lípez, no 3224, sin fol.

78 El Ferrocarril (Oruro, 15 de agosto de 1906): 2.

79 Bacarreza, [1912] 2006: 385. 
do de la República de Chile por las vías de Llica y San Pedro» ${ }^{80}$; en 1929 , por último, el prefecto de Oruro comunicaba que en la provincia a su cargo apenas habían «tres policías» en los pueblos de Corque, Sajama y Sabaya y que además en las últimas dos localidades, fronterizas a Chile, los locales policiales eran «inadecuados y carecen de los muebles más indispensables así como de armamento» ${ }^{81}$.

Ante la evidencia de la imposibilidad sistémica de controlar el tráfico fronterizo, la actitud de muchos funcionarios fiscales chilenos fue poner el acento sólo en la regulación de la circulación del ganado y no hacer mayor pábulo del tráfico de las otras mercaderías. Este fue el caso del subdelegado Atrimpel que, ante la denuncia realizada en junio de 1913, sugirió a sus superiores exclusivamente medidas de control respecto a la venta de ovejas y llamas que provenía de la cordillera ${ }^{82}$. No debe llamar la atención que este subdelegado centrara su atención en el problema del tráfico ganadero y no extendiera su preocupación hacia la comercialización de las otras numerosas mercancías que penetraban cada vez con mayor frecuencia y volumen desde la frontera con Bolivia. En efecto, este funcionario, junto a gran parte del aparato administrativo chileno asentado en la provincia de Tarapacá, era de la opinión de que el contrabando de charqui, lanas, papa chuño, tejidos, etc., era un mal menor tanto por el bajo valor de las tasas implicadas como por el hecho de que satisfacía significativamente las necesidades más básicas de abastecimiento que requería el numeroso y creciente contingente humano que trabaja en las oficinas salitreras, rasgos que la internación de ganado al margen de las regulaciones aduaneras por parte de comerciantes indígenas del lado boliviano y chileno no tenía, especialmente por el volumen del impuesto que se evadía.

El efecto inmediato que tuvo esta escasa fiscalización estatal en Tarapacá fue un incremento exponencial del contrabando de mercancías desde y hacia Bolivia, aspecto que llevó en 1914 al intendente Ricardo Beaugency a solicitar al ministro de Hacienda la restitución del servicio de Resguardo de Frontera que se había cerrado dos años antes ${ }^{83}$. La amplitud alcanzada por este tráfico mercantil al margen de las disposiciones legales chilenas, llevó a que en la década de 1920 algunas autoridades locales vinculadas principalmente a las subdelegaciones adscritas a la zona andina buscaran, mediante una in-

\footnotetext{
80 San Cristóbal, 4/10/1911, AHP, FPD, Subprefectura Nor Lípez, n³636, sin fol.

81 González, 1929: 31.

82 Tarapacá, 5/6/1913, ARI, IT, Subdelegaciones, 1913, vol. 9, sin fol.

${ }^{83}$ Iquique, 31/3/1914, ARI, IT, Copiador de Oficios a los Ministerios, 1914, vol. 14, fol. 162 .
} 
tervención más directa de la policía, poner coto a la evasión tributaria. Es el caso detallado el 3 de marzo de 1923 por el comandante del Primer Regimiento de Carabineros, Luis Marchant, al comunicarle al intendente que por «ordenes reservadas» había desplegado en el departamento de Pisagua, a fin de de constatar y regular sus procedimientos, «activa vigilancia y fiscalización de arrieros» y «elementos peruanos» que constantemente viajaban por los caminos fronterizos ${ }^{84}$; también la situación derivada de la presentación realizada en marzo de 1928 por parte del agricultor y comerciante Dionicio Mamani Pérez, residente en Coscaya, al intendente de la provincia reclamando por el impedimento que le hacía carabineros al libre comercio de sus productos en la pampa salitrera a pesar que cumplía con las leyes del país ${ }^{85}$.

Estas acciones más incisivas de carabineros durante la década de 1920 al tráfico mercantil andino fue una respuesta parcial, no siempre respaldada y reconocida por la autoridades asentadas en Iquique, de frenar, por una parte, la disposición de numerosos comerciantes (indígenas o no indígenas, bolivianos y/o peruanos, y también chilenos) de ejercer la internación de mercancías evitando la cancelación de los aranceles aduaneros, una práctica que a los largos de los años se había hecho tan recurrente al punto de representar una de las características de este tipo de comercio transfronterizo, y, por otra, intentar revertir la carencia de agentes fiscalizadores y de acciones fiscalizadoras, una debilidad que había terminado avalando y posibilitando lo anterior. En este sentido, la acción policial se abocó no sólo a vigilar la llegada de mercancías sino también a verificar la salida de productos hacia Bolivia. En esta tarea no fueron pocos los obstáculos que se le presentaron a estos nuevos policías, sobre todo el arrastre de una burocracia que poca atención le había prestado a la implementación administrativa en el interior de la provincia. Así se lo señaló, el 11 de julio de 1928, Ernesto Gómez Delgadillo en su calidad de encargado de la Aduana de Iquique al intendente Luis Caballero al observarle que el tema respecto al comercio de los indios bolivianos no es:

solicitar a US. para que ellos tengan excepción del Arancel Aduanero, sino con su elevada investidura solicite, siempre que lo estime conveniente, de quién corresponda el envío de un empleado de Aduana... ${ }^{86}$.

Otro ámbito en el cuál la autoridad buscó poner mayor control en esta década fue en el ingreso de ganado, actividad mercantil que representaba el

84 Tacna, 3/3/1923, ARI, IT, Varios Informes, 1925, vol. 2, sin fol.

85 Iquique, 1/3/1928, ARI, IT, Solicitudes, 1927, vol. 25, sin fol.

86 Iquique, 11/7/1928, ARI, IT, Solicitudes, 1927, vol. 25, sin fol. 
mayor volumen del tráfico que por lo general no paga impuestos de internación. A este efecto se comenzó a exigir, con relativo éxito, la inscripción de los animales con el propósito de poder distinguir cuales pertenecía a propietarios residentes del lado chileno respecto de los que ingresaban desde Bolivia. Aquí tenemos el caso, fechado en el pueblo de Pica en el mes de octubre de 1927, de la solicitud del ganadero indígena Alejandro Arroyo de que le emitieran un certificado de inscripción de sus animales (950 ovejas, 380 con crías; 45 cabras, 40 con crías; y 700 llamas, 380 con crías) que pastaban en distintos corrales que se ubicaban en Alca y la laguna del Huasco ${ }^{87}$. La razón argüida era que «ante la noticia del aumento de vigilancia para evitar el contrabando» quería «evitar que las autoridades o carabineros [incurrieran] en considerar este ganado como procedente de Bolivia o Argentina» ${ }^{8}$. En el mes de mayo de 1931, argumentando las mismas razones de Arroyo, los ganaderos aymaras Exequiel Ticona, Celestino Lucas y Juan Cruz Lucas proceden a pedir la actualización de certificados de inscripción de sus ganados respecto a unos que se habían otorgado originalmente entre el 18 y el 31 de diciembre de $1926^{89}$. Ticona lo hacía respecto a 180 ovejas, 38 cabras y 70 llamas que estaban en los corrales Peña Blanca y Pabellón en la laguna del Huasco. Por su parte Cruz Lucas en consideración de 150 ovejas, 20 cabras y 80 llamas que pastaban en los corrales Peña Blanca y Sillillica también en la laguna del Huasco. Por último Lucas en referencia a 10 cabras, 150 ovejas y 100 llamas que tenía en el corral ya mencionado de Peña Blanca ${ }^{90}$. Al amparo de esta misma dinámica, en noviembre de 1931 Patricio Vilca, que se identificaba como agricultor y chileno, residente en la quebrada de Coscaya, demandaba la entrega del certificado de inscripción de 80 llamas y 100 corderos que poseía tanto en la mencionada quebrada de Coscaya como en Pirgua. Como argumento para validar su petición mencionaba que sus animales eran de

${ }^{87}$ Los corrales eran: Atipinga, Pucarita, Alca, Laguna del Huasco, Huasco Lípez, Pabelloncito, Calacaja, La Banda de Ocuna y Potreros.

88 Pica, octubre 1927, ARI, IT, Solicitudes, 1931, vol. 4, sin fol.

89 Los certificados de inscripción otorgados en 1926 no sólo fueron para los ganados de Exequiel Ticuna, Celestino Lucas y Juan Cruz Lucas, sino también para 200 ovejas y 100 llamas de Ildefonso Luna que estaban en Agua de Pula; 181 llamas, 2 cabras y 60 ovejas de Genaro Carlos en la hacienda Copa de Cancosa; 100 llamas y 100 ovejas de Enrique Latorre en Cancosa; 100 ovejas y 80 llamas de Silverio Vilca en el corral de Aguaypula; 93 llamas de Eugenio Ignacio en Jalaja (cerro de Polquesa); 500 ovejas y 200 llamas de Martín Yañez en el pago de Sacaya en Cancosa; 500 0vejas y 500 llamas de Tomás Cáceres en Collocagua y Sila; 100 ovejas, 120 cabras y 120 llamas de Pablo Ticona en el corral Peña Blanca y 270 ovejas, 40 cabras y 300 llamas de Esteban Yáñez también en Peña Blanca.

90 Pica, 28/5/1931, ARI, IT, Solicitudes, 1931, vol. 4, sin fol. 
«crianza chilena» y que desde su «infancia pasteaba sus animales en el lado chileno» ${ }^{91}$.

A pesar de este resguardo tardío de carabineros, la dinámica impuesta por décadas de funcionamiento permitió cierta permeabilización persistente de este comercio transfronterizo, no siendo pocas las veces que se procedió de manera contradictoria a la hora de fiscalizar aquello que se consideraba contrabando. Así le ocurrió en 1930 al ganadero aymara Manuel Segundo Aguirre, residente de Sillillica, que obtuvo un permiso de palabra por parte del Sargento Francisco Osses Peña para bajar desde la frontera al pueblo de Pica con sus recuas de llamas cargadas de papa chuño y quínua sin contar con el pasaporte correspondiente ${ }^{92}$. Días más tarde este comerciante es detenido en el oasis piqueño por contrabando, una situación que lo lleva a entablar una recusación judicial contra el mencionado policía ${ }^{93}$.

En efecto, la solidez de la dinámica sociocultural y el peso económico del tráfico mercantil andino hizo que estos intentos de regulación no prosperaran. Así lo corroboró, en 1926, el propio intendente de Tarapacá cuando, en una contestación al gobernador de Pisagua, de manera muy clara señalaba:

En cuanto a los $[\ldots]$ contrabandos que se introducen de Bolivia, considero casi imposible evitarlos. La frontera es abierta y puede ser atravesada en cualquier parte, sobre todo por los indios bolivianos acostumbrados a hacer grandes caminatas a pie y por senderos intransitables para caballos y mulas ${ }^{94}$.

Si esta observación no fue suficiente, dos años más tarde, en abril de 1928, la máxima autoridad política de la provincia de Tarapacá nuevamente reitera sus dichos en un oficio remitido al administrador de la Aduana de Iquique, esta vez dando cuenta del informe que le había hecho llegar el inspector del Distrito de la Guayca, Lizandro Bruna Garrido, respecto a las «grandes partidas de indios conduciendo numerosas llamas y ganado de contrabando». A su entender los llameros indígenas no sólo «proceden con entera libertad» ante la falta de personal de carabineros, sino además la actividad mercantil que ejecutan «beneficia el consumo de los pueblos del interior» ${ }^{95}$. Por si fuera poco, en agosto de 1929, el secretario de la Intendencia, Humberto Galindo, por orden directa del intendente Nemesio Valenzuela, tajantemente le comunica al inspector del Distrito de Mamiña:

\footnotetext{
91 Huara, 25/11/1931, ARI, IT, Solicitudes, 1931, vol. 4, sin fol.

92 Pica, 1/12/1930, ARI, IT, Solicitudes, 1930, vol. 16, sin fol.

93 Iquique, 6/12/1930, ARI, IT, Solicitudes, 1930, vol. 16, sin fol.

94 Iquique, 17/9/1926, ARI, IT, Oficios Generales, 1926, vol. 8, sin fol.

95 Iquique, 13/4/1928, ARI, IT, Oficios Generales, 1928, vol. 30, sin fol.
} 
Se ha tenido conocimiento en esta Intendencia de que a los indios bolivianos del interior se le cobran ciertos derechos por sus animales.

Como tales cobros son ilegales y se encuentran penados en el Código Penal, me permito manifestarle que las autoridades deben abstenerse en lo sucesivo de hacer tales cobros, haciéndole presente que si se tienen nuevas noticias sobre el particular se ordenará una investigación a fin de aplicar las sanciones que correspondan ${ }^{96}$.

Al no haber un patrón de control estatal directo, las poblaciones aymaras (del lado chileno y boliviano) pudieron desenvolverse en lo tocante a dinámicas de intercambio mercantil sin ninguna presión agobiante, salvo las irregulares y esporádicas acciones por lograr que cancelaran derechos aduaneros. De esta manera, el comercio hacia los reductos pampinos más que reflejar una degradación impuesta a la estructura social de los habitantes andinos, estructura que por lo demás estaba en transición a perfiles modernizadores endógenos desde hacía bastante tiempo atrás ${ }^{97}$, reflejó una inserción premeditada de estos habitantes indígenas a las dinámicas económicas derivadas por la influencia del enclave salitrero y su creciente demanda de bienes de consumo ${ }^{98}$.

\section{LOS COMERCIANTES INDÍGENAS Y LOS AGENTES FISCALES: NEGOCIACIÓN Y CONFLICTO}

En toda la extensión del ciclo de expansión del salitre la intervención inescrupulosa y fuera de la ley de funcionarios administrativos tanto chilenos como bolivianos en el tráfico mercantil andino no fue menor. Por parte de los comerciantes indígenas la interacción con este tipo de personajes tuvo que ver con un decidido propósito de minimizar -en un escenario de cambios y, por lo mismo, de incertidumbres- los riesgos inherentes a la mantención de una modalidad de intercambio comercial de larga data, especialmente en lo que tocaba, en tanto una amenaza sistémica, a la reconfiguración del espacio con nuevas delimitaciones (y formas legales) fronterizas; pero además, sobre todo para aquellos indígenas que residían en las cercanías de la frontera, este tipo de vínculos se entendía como una modalidad para seguir practicando lógicas

\footnotetext{
96 Iquique, 8/8/1929, ARI, IT, Oficios Generales, 1929, vol. 19, sin fol.

97 Carolina Figueroa, 2008, describe esta temprana dinámica modernizadora para la década de 1820, especialmente en un registro de indígenas comerciando con regularidad con los laboreos mineros cercanos al pueblo de La Tirana.

98 Esta inserción operó en dos ámbitos complementarios: la producción agrícola y su comercialización orientada a los requerimientos de la población que laboraba en la industria salitrera, y la migración estacional como trabajadores asalariados.
} 
de complementariedad que ahora se veían trabadas por la emergencia de nuevas agencialidades estatales, nacionales y fronterizas. En tanto, respecto a los funcionarios fiscales de ambos lados de la frontera, el asunto tuvo ribetes en gran parte centrados en la generación de ganancias monetarias mal habidas.

De este modo, la intervención de agentes fiscales chilenos y bolivianos en el tráfico mercantil andino escenificó, por una parte, dinámicas de negociación y conflicto al margen de las tensiones propias que representaba para las poblaciones indígenas la presencia por sí sola del aparato estatal chileno, y, por otra, la evidente debilidad de la presencia de esta agencia estatal en los recónditos lugares de los Andes de Tarapacá.

Un primer antecedente disponible que grafica esta situación es la denuncia cursada en agosto de 1911 por parte de José Gil Luza, vecino de Sotoca, en contra de un tal Carlos Atencio, aparentemente de nacionalidad boliviana, por el cobro que estaba realizando a los ganaderos y arrieros de los altos de Sotoca de un importe de $\$ 50$ cada dos meses por concepto de ocupación de pastizales y tráfico de ganado mediante el argumento de que la mencionada localidad, junto a los pueblos de Sipiza y Huasquiña, pertenecía a la jurisdicción de Pisagua -a la cual él decía representar- y no a la de Tarapacáa9. En septiembre de 1913, en tanto, el inspector del Distrito de Camiña Ramón Fuentes acusa, poniendo en el tapete los alcances que tenía el tráfico ilegal en la frontera, al inspector del Cantón boliviano de Moquella, José Bacilio Zevallos, como dueño de una partida de salitre destinada a ser contrabandeada hacia Bolivia en complicidad con Miguel Vilca un ganadero aymara de la zona de Isluga ${ }^{100}$.

Este tipo de sociedad con agentes a ambos lados de la frontera fue muy recurrente en el negocio de la internación de salitre hacia Bolivia como en el tráfico de ganado desde el vecino país hacia la pampa salitrera, especialmente porque facilitaba afianzar ciertos mecanismos al límite de lo legal, o derechamente fuera de la ley, destinados a evitar el tener que pagar los derechos de aduana en uno y otro territorio nacional. Así, la composición de este tipo de sociedad no se remitía exclusivamente a la participación de comerciantes indígenas o mestizos residentes en lugares aledaños a la frontera, sino principalmente a la presencia de individuos que ocupaban cargos administrativos en los lugares por donde estaban las rutas de internación. Por lo mismo, este tipo de práctica rápidamente se transformó en un artilugio bien estructurado que posibilitaba sobrepasar con éxito la escasa fiscalización policial fronteriza.

99 Tarapacá, 9/8/1911, ARI, IT, Subdelegaciones, 1911, vol. 47, sin fol.

100 Camiña, 6/9/1913, ARI, IT, Censo, 1920, vol. 19, sin fol. 
Una buena muestra de lo anterior es el caso denunciado el 2 de junio de 1917 por el jefe de la Guarnición de Pozo Almonte, Fernando Matías Godoy, que comprometía al subdelegado de Pica, Ramón Luis Moya, como el principal integrante de una banda que introducía ganado clandestinamente a los cantones salitreros de Tarapacá y el Toco ${ }^{101}$. Esta sociedad ilícita funcionaba mediante la utilización de un permiso debidamente registrado por una cantidad media de animales gestionada por el mismo subdelegado de Pica que, al amparo de su investidura, lograba presentar en distintas ocasiones a los funcionarios policiales que lo requerían; de este modo con un mismo documento lograba justificar la totalidad del ganado que traía desde Bolivia evitando el pagar los derechos aduaneros:

...estos animales venían de Alca y pasaron por la Calera y si el señor Moya presentó póliza ya no tenía ninguno por cuanto sus animales ya han pasado, datos recojidos por el que suscribe en acciones al interior, dichos corderos deben [posesión] a José Barrera que hasta este momento no ha presentado póliza ninguna, y cuando se ve sorprendido por la policía recurre a las de Moya. Barrera tiene animales en Alca [ilegible] y que bajará a más tardar el veinte del presente mes sino a Pozo Almonte a Huara por [camino] de San Donato y hará la misma [trampa] en caso de ser sorprendido nuevamente, pero el punto principal para la aprensión es la [frontera] donde no puedo trasladarme por tener los soldados de guarnición ocupado en una misión encargada por la Prefectura en el sondaje de petróleo.

Alejandro Arroyo también presentó póliza por quinientos corderos para internación, según averiguaciones practicadas trae ochocientas cabezas, lo que deja manifiesto que pasará trescientas clandestinamente.

Lo que hay de cierto es que estos señores pasan cierta cantidad de animales por un punto tanto por otro, y así sucesivamente y en caso de ser sorprendidos dicen además de mostrar la póliza las demás las pasaré por tal parte, valiéndose de la trama pasan un número mayor de animales a que la póliza se refiere ${ }^{102}$.

Aún más explícito sobre este proceder fue el comisario de Investigaciones de Iquique cuando, en un informe dirigido con fecha 8 de junio de 1918 al intendente de Tarapacá, ratificaba que Ramón Luis Moya era quién introducía ganado desde Bolivia utilizando una póliza que acreditaba el pago de $\$ 1.498$ por derechos correspondientes a 600 corderos. Específicamente señalaba que, al no haber vigilancia y fiscalización en los pueblos del interior, quedaba a la voluntad de los traficantes de ganado «el tramitar o no las pólizas correspon-

101 Iquique, 5/6/1917, ARI, IT, Censo, 1920, vol. 19, sin fol.; Pica, 19/6/1917, ARI, IT, Censo, 1920, vol. 19, sin fol.

102 Pica, 19/6/1917, ARI, IT, Censo 1920, vol. 19, sin fol. 
dientes, siendo el caso corriente que con una póliza por una pequeña cantidad de animales se introduzcan partidas mucho mayores» ${ }^{103}$.

La búsqueda de provecho económico por parte de este tipo de funcionarios fiscales no sólo se acotó a la participación en sociedades informales, sino también se materializó mediante un ejercicio abusivo y arbitrario hacia los comerciantes andinos que no disponían de un socio (o no querían tenerlo) bien ubicado en la trama burocrática del aparato fiscal chileno asentado en la provincia de Tarapacá. En estos casos lo que se hacía, de modo puntual por policías asignados a las subdelegaciones rurales andinas (Camiña, Tarapacá, Pica, Challacollo), era cobrarles derechos de aduana que no tenían como destino las arcas fiscales sino los «bolsillos particulares», un procedimiento que se aplicaba incluso sobrepasando la autoridad de funcionarios fiscales de mayor rango. Precisamente de esta forma obró un piquete de policías comandados por el jefe de la Guarnición de Pica al detener el 3 de marzo de 1917 a los indios Pedro Quispe y Fructuoso Mamani cuando se dirigían hacia Bolivia con llamas cargadas con víveres que se habían adquirido en el oasis piqueño ${ }^{104}$. Aduciendo los policías que estos comerciantes indígenas lo que llevaban era alcohol (vino, aguardiente, cerveza) y no víveres, procedieron a detenerlos en el cuartel hasta que no abonaran $\$ 4$ por cada llamo cargado en consideración a los derechos de salida por la frontera. Lamentablemente para las pretensiones de estos policías, intervinieron a favor de los comerciantes indígenas el nuevo subdelegado de Pica, J. Robles, y el cónsul de Bolivia en Iquique, Arístides Moreno, a petición del residente boliviano de Pica Pío Mercado. Ambos recurrieron al intendente quién dio instrucciones precisas de liberación inmediata, sin que antes los policías desconocieran la autoridad del subdelegado y sólo rectificaran su posición una vez trasmitida la orden de la máxima autoridad política de la provincia usando como argumento que no tenía conocimiento del nombramiento de Robles como interino ${ }^{105}$.

Evidentemente la acción como la actitud arbitraria de estos policías asentados en Pica se entienden en el contexto de la conducta de quién había sido, suponemos hasta febrero de 1917, el subdelegado titular de esta jurisdicción, nuestro ya conocido Ramón Luis Moya. Es probable que el jefe de la Guarnición de Pica y sus subalternos también hayan estado involucrados en los negocios de Moya y, por tanto, contase con la protección de este último a la

103 Iquique, 8/6/1918, ARI, IT, Arriendo Terrenos Fiscales, 1918, vol. 3, sin fol.

104 De acuerdo a la información del residente boliviano de Pica, Pío Mercado, en nota dirigida al Cónsul de Bolivia en Iquique, los detenidos eran 4 indios y no 2 como señalaba el parte de la Subdelegación de Pica.

105 Pica, 1/3/1917 y 5/3/1917, ARI, IT, Intendencia de Tarapacá, 1917, vol. 17, sin fol. 
hora de buscar formas de exacción ilegal a los comerciantes indígenas. En estos términos, y haciendo un mal cálculo, hayan actuado estando convencidos que el nuevo subdelegado por su condición de interino no se iba a entrometer en los «negocios» de Moya.

La situación descrita para 1917 se reiterará en 1930 cuando el sargento de policía, José Osses Peña, en una inspección de rutina procede a detener en los pastales de Sillillica, muy próximo a la frontera, a Manuel Segundo Aguirre que conducía 49 llamas con carga diversa destinada al pueblo de Pica. De acuerdo al comerciante indígena ${ }^{106}$, al entrar en contacto con el mencionado funcionario policial le había señalado que no portaba el pasaporte (o póliza) ante lo cual éste le dijo «que no importaba, que pasase nomás y que eso se arreglaría después». Confiado en este permiso, entonces habría seguido hacia el oasis piqueño, lugar en donde apenas llegó fue detenido, junto con sus acompañantes, por la misma fuerza policial aduciendo el ejercicio de contrabando por no contar con la documentación requerida que lo autorizaba para tal efecto ${ }^{107}$. En tanto, la versión del funcionario policial señala que al no contar Manuel Segundo Aguirre con el pasaporte y la guía de libre tránsito inmediatamente fue detenido, junto a sus acompañantes, en el punto de Miraflores, siendo trasladados al retén de Pica en donde fueron puestos a disposición del Juzgado de Menor Cuantía ubicado en el pueblo salitrero del Alto San Antonio ${ }^{108}$.

Si bien es difícil constatar cual de las dos versiones es la fidedigna, no debe resultar raro, porque los antecedentes disponibles así lo permiten, inferir que en esta ocasión estemos en presencia de un intento frustrado entre los policías comandados por el sargento José Osses y el llamero indígena Segundo Aguirre por tratar de llegar a un acuerdo pecuniario al margen de lo legal. Lo interesante es que este tipo de práctica delimitó y potenció ciertas dinámicas de conflicto como de negociación sólo posible por la agencialidad distante del Estado chileno en el espacio andino tarapaqueño. En otras palabras, la falta de fiscalización ante la carencia regular de recursos estatales (léase carencia de funcionarios, falta de oficinas públicas, desinterés por los cargos rurales, etc.) dio pie para que tanto los comerciantes y arrieros andinos como ciertos funcionarios fiscales actuaran siguiendo sus propias lógicas e intereses.

106 La presentación de Manuel Segundo Aguirre fue realizada por Agustín Lázaro al no saber escribir y leer el primero.

107 Pica, 1/12/1930, ARI, IT, Solicitudes, 1930, vol. 16, sin fol.

108 Iquique, 6/12/1930, ARI, IT, Solicitudes, 1930, vol. 16, sin fol. 


\section{Comentarios finales}

Es evidente que a lo largo del ciclo salitrero comprendido entre las décadas de 1880 y 1930 el tráfico mercantil andino tuvo un rol fundamental para la economía regional. Sin este el abastecimiento de los centros urbanos pampinos y costeros asociados a la explotación salitrera hubiese estado en grandes dificultades, y por lo mismo logró sortear con éxito la compleja y difícil transición del paso del territorio de Tarapacá desde la administración peruana a la chilena; un aspecto nada menor si tomamos en cuenta que este tipo de comercio tenía su eje en la circulación transfronteriza. Esta condición, enmarcándola, eso sí, en una visión más amplia de la economía tarapaqueña y su vinculación con Bolivia, rápidamente fue asumida por distintas autoridades políticas chilenas asentadas en Iquique, sobre todo por algunos intendentes ${ }^{109}$, lo que le posibilitó al tráfico mercantil andino durante las décadas de 1880 y 1930 tener un margen de movilidad nada despreciable, especialmente en lo que le tocaba a la evasión de la fiscalización.

Por otro lado, la convivencia del tráfico mercantil de insumos desde y hacia Bolivia ejecutado principalmente por comerciantes indígenas y el arrieraje proveniente del noroeste de Argentina bajo un patrón mercantil-capitalista más marcado, fue un resultado nada contradictorio con los intereses chilenos en la zona, como tampoco incoherente en lo que se refiere a la inserción de los indígenas al modernizador sistema económico articulado en torno al enclave salitrero. En efecto, a diferencia de los arrieros provenientes del noroeste argentino que regularmente terminaban su trayectoria en los pueblos y oficinas salitreras, la mayoría de los comerciantes (muchos de ellos llameros) provenientes de la frontera boliviana, regularmente, llegaban sólo a localidades rurales no pampinas como Camiña, Mamiña, Chusmiza y Pica para llevar a cabo el intercambio de los productos que transportaban desde el altiplano y la sierra ${ }^{110}$, bajando ocasionalmente de manera directa a la pampa salitrera. De este modo se mantuvo, hasta bien entrado el ciclo salitrero, cierto equilibrio entre dos modalidades paralelas y complementarias a la vez: el intercambio monetario (que se ejecutaba en las oficinas y pueblos salitreros) y el intercambio no monetario (en los pueblos rurales de la pre-cordillera), conformando un mercado específico y singular (el andino), al estar sustentado tanto en el comercio como en el trueque. De acuerdo a Hanne Cottyn los viajes desde Carangas a Tarapacá destinados al trueque ocurrían puntualmente en los momentos de fiestas y ferias (como lo describió Alejandro Bertran

109 Sobre este punto ver: Castro, 2005: 93-124.

110 González, 1989: 24-25. 
para Chuzmiza en 1879), siendo los restantes desplazamientos de orientación preferentemente mercantil-monetarista ${ }^{111}$.

De este modo, se reprodujeron sin mayor conflicto diversos mecanismos étnico-económicos articulados en torno a la dinámica centripetadora del enclave minero del salitre, un rasgo que terminó por solventar la persistencia del comercio controlado por indígenas desde y hacia Bolivia incluso más allá del ciclo salitrero ${ }^{112}$.

\section{BiBLIOGRAFÍA}

Alfaro, Carlos, Reseña histórica de la Provincia de Tarapacá, Iquique, Imprenta Caras y Caretas, 1936.

Bacarreza, Zenón, "Informe técnico sobre la provincia de Carangas (1910)", Magdalena Cajías et al., Ensayos históricos sobre Oruro, La Paz, IEB/SIERPE, 2006: 350-404.

Bertrand, Alejandro, Departamento de Tarapacá. Aspecto jeneral del terreno, su clima $i$ sus producciones, Santiago de Chile, Imprenta de la República, 1879.

Caro, Gregorio, "Salitre y ganado. Base de un intercambio regional", María Mora y Pablo Romero (comp.), NOA-Norte Grande. Crónica de dos regiones integradas, Santiago de Chile, Embajada de Argentina en Chile, 1999: 146-149.

Castro, Luis, "Historia de la minería no salitrera de la provincia de Tarapacá", Lautaro Núñez y Cecilia García Huidobro (coords.), Patrimonio Cultural de la Provincia de Iquique. Región de Tarapacá, Santiago de Chile, Compañía Minera Doña Inés de Collahuasi-Corporación del Patrimonio Cultural de Chile, 2002: 353-368.

Castro, Luis, Regionalismo y Desarrollo Regional: debate público, proyectos económicos y actores locales (Tarapacá 1880-1930), Viña del Mar, CEIP Ediciones-Universidad de Valparaíso-Universidad Santo Tomás, 2005.

Castro, Luis, "Minería de altura y dinámicas de población boliviana e indígena en el norte de Chile (Tarapacá 1880-1930)", Revista de Estudios Transfronterizos Si Somos Americanos, Iquique-Chile, Universidad Arturo Prat, 2010: 129-145.

111 Cottyn, 2011: 34.

112 Por ejemplo, hacia la década de 1960 todavía es posible encontrar registros de este tipo de intercambio, como el juicio iniciado a mediados de 1962 por parte del Juez-Administrador de Aduanas de Iquique en contra del boliviano Lino Calisaya Calle avecindado, y con familia chilena, en el pueblo de Camiña por el tráfico de 4,5 kilos de hoja de coca y 15 kilos de lana de llama (Pisagua 27/8/1962, ARI, Judicial de Pisagua, Juzgado del Crimen, legajo 1, caja 2 , vol. 5683 , folios $1 \mathrm{v}-58 \mathrm{r}$ ). 
Conti, Viviana, "Entre la plata y el salitre. Los mercados del Pacífico para las producciones del norte argentino (1830-1930)", Viviana Conti y Marcelo Lagos (comp.), Una tierra y tres naciones. El litoral salitrero entre 1830 y 1930, Jujuy, Editorial de la Universidad Nacional de Jujuy, 2002: 119-149.

Conti, Viviana, "El noroeste argentino y Atacama: producción y mercados", Alejandro Benedetti (comp.), Puna de Atacama. Sociedad, economía y frontera, Córdoba, Alción Editora, 2003: 21-52.

Conti, Viviana, "La ruta de los arrieros y el salitre", Ángel Cabezas, María Isabel Hernández, Lautaro Núñez y Mario Vázquez (ed.), Las rutas del capricornio andino. Huellas milenarias de Antofagasta, San Pedro de Atacama, Jujuy y Salta, Santiago de Chile, Consejo de Monumentos Nacionales, 2006: 93-104.

Cottyn, Hanne, La reorientación de las comunidades de Carangas dentro de los circuitos económicos del espacio andino (1860-1930), Oruro, Centro de Investigaciones Políticas y Sociales, 2011. Cuadernos de Investigación $\mathrm{n}^{\circ} 2$.

Espinoza, Enrique, Jeografía descriptiva de la República de Chile, Santiago de Chile, Imprenta i Encuadernación Barcelona, 1897.

Figueroa, Carolina, "Espacios andinos, pastores aymaras y el tráfico de salitre (Tarapacá 1880-1930)", Viña del Mar, Ponencia VIII Encuentro Boliviano-Chileno de Cientistas Sociales, Historiadores e Intelectuales, 2008.

Gajardo, Yeliza y Díaz, Alberto, Las aguas de la identidad. Chusmiza, historia y conflicto en la precordillera tarapaqueña, Chusmiza, CONADI (Concurso Regional de Arte y Cultura Uywir T'alla), 2008.

González, Raimundo, Informe del Prefecto del Departamento de Oruro, Oruro, 1929.

González, Sergio, "El arrieraje en Tarapacá durante el ciclo salitrero", Camanchaca, 8 (Iquique, 1989): 10-35.

González, Sergio, Hombres y mujeres de la pampa. Tarapacá en el ciclo del salitre, Iquique, Ediciones Especiales Camanchaca, 1991.

González, Sergio, "El arrieraje argentino y las salitreras", María Mora y Pablo Romero (comp.), NOA-Norte Grande. Crónica de dos regiones integradas, Santiago de Chile, Embajada de Argentina en Chile, 1999: 60-65.

González, Sergio, Chilenizando a Tunupa. La escuela pública en el Tarapacá andino 1880-1990, Santiago de Chile, Coedición DIBAM/Universidad Arturo Prat/Centro de Investigaciones Barros Arana, 2002.

González, Sergio, Arica y la triple frontera. Integración y conflicto entre Bolivia, Perú y Chile, Iquique, Ediciones Aríbalo, 2006a.

González, Sergio, "La presencia indígena en el enclave salitrero de Tarapacá: una reflexión en torno a la fiesta de La Tirana", Chungara, 38/1 (Arica, 2006b): 35-49. 
González, Sergio, "La presencia boliviana en la sociedad del salitre y la nueva definición de la frontera: auge y caída de una dinámica transfronteriza (Tarapacá 1880-1930)", Chungara, 41/1 (Arica, 2009): 71-81.

Morales, Constantino, Informe del Prefecto y Comandante General del Departamento, Oruro, 1913.

Michel, Azucena, Pérez, Lilia y Savic, Elizabeth, "Exportaciones de Salta al norte chileno. Fines del siglo XIX y comienzos del XX”, Estudios Trasandinos, 2 (Santiago de Chile, 1998): 99-113.

Pauwels, Glberto, “Carangas en el año 1910. El informe de Zenón Bacarreza”, Magdalena Cajías et al., Ensayos históricos sobre Oruro, La Paz, IEB y SIERPE, 2006: 337-349.

Van Kessel, Juan, Holocausto al progreso. Los aymaras de Tarapacá, La Paz, HISBOL, 1992.

Fecha de recepción: 5 de noviembre de 2012.

Fecha de aceptación: 21 de diciembre de 2012.

\section{Andean Commercial Trade, Indigenous Traders and State Supervision and Control (Tarapacá, northern Chile 1880-1938)}

This article addresses the intense and relevant commercial trade carried out in the old Tarapacá province by traders and indigenous Aymara muleteers coming from both sides of the Andean border area of Chile and Bolivia during the saltpeter cycle. In addition to emphasizing the impacts and characteristics of this style of commercial trade and its ethnic component, the attention is focused on the complex relationship with the Chilean fiscal officers considering that the chilenization process was already underway.

KEY WORDS: commercial trade; Aymara; state supervision and control; chilenization. 